\title{
Range of motion and muscle strength deficits of patients with total hip arthroplasty after surgery
}

Authors' Contribution: A Study Design

B Data Collection

C Statistical Analysis

D Data Interpretation

E Manuscript Preparation

F Literature Search

G Funds Collection

\author{
Aykut ÖzçadırcI ${ }^{1 B C E F}$, Ömür Çağlar ${ }^{2 A D}$, Gürsoy Coșkun ${ }^{1 A C D}$ \\ ${ }^{1}$ Faculty of Physical Therapy and Rehabilitation, Hacettepe University, Ankara, Turkey \\ ${ }^{2}$ Department of Orthopaedics and Traumatology, Faculty of Medicine, \\ Hacettepe University, Ankara, Turkey
}

\section{abstract}

Background: The aim of this study was to compare muscle strength and range of motion of the operated and unoperated side and to determine the relationship between the functional status and muscle strength and range of motion in patients with Total Hip Arthroplasty (THA) 1-3 years after surgery.

Material and methods:

50 patients with THA were assessed after surgery in this study. A universal goniometer was used to measure the range of motion (ROM). Muscle strength was measured by a hand-held dynamometer. The patients' functional status was determined with the Oxford Hip Score (OHS).

Results: The difference in hip abduction and knee extension muscle strength between operated and unoperated side was statistically significant $(p<0.05)$. Also, there was a difference between the operated and unoperated side in the hip ROM in favor of the unoperated side in all ROM except adduction $(p<0.05)$. There was a moderate correlation between OHS and muscle strength.

Conclusions: This study emphasizes the importance that these patients need physiotherapy programs in the long term and should be followed up regularly by healthcare professionals in the rehabilitation area. Finally, restoring muscle strength and range of motion is recommended to improve the functional state in daily life activities.

Key words: hip arthroplasty, muscle strength, range of motion, deficit, long-term.

\section{article details}

Article statistics: Word count: 3,118; Tables: 5; Figures: 4; References: 25

Full-text PDF: http://www.balticsportscience.com

Copyright @ Gdansk University of Physical Education and Sport, Poland

Indexation: Celdes, Clarivate Analytics Emerging Sources Citation Index (ESCI), CNKI Scholar (China National Knowledge Infrastructure), CNPIEC, DOAJ, EBSCO - Central \& Eastern European Academic Source, EBSCO - SPORTDiscus, EBSCO Discovery Service, Google Scholar, Index Copernicus, J-Gate, Naviga (Softweco, Primo Central (ExLibris), ProQuest - Family Health, ProQuest - Health \& Medical Complete, ProQuest - Illustrata: Health Sciences, ProQuest Nursing \& Allied Health Source, Summon (Serials Solutions/ProQuest, TDOne (TDNet), Ulrich's Periodicals Directory/ ulrichsweb, WorldCat (OCLC)

Funding: This research received no specific grant from any funding agency in the public, commercial, or not-for-profit sectors.

Conflict of interests: Corresponding author:

Open Access License:
Authors have declared that no competing interest exists.

Aykut Özçadırcı, Hacettepe University, Faculty of Physical Therapy and Rehabilitation, Ankara, Turkey, 06100; phone no.: +90 31230525 25; fax: +90 31230515 76; e-mail: aykutozcadirci@gmail.com

This is an open access article distributed under the terms of the Creative Commons Attribution-Non-Commercial-NoDerivatives 4.0 International (https://creativecommons.org/licenses/by-nc-nd/4.0/), which permits use, distribution and reproduction in any medium, provided the original work is properly cited, the use is non-commercial and is otherwise in compliance with the license. 


\section{INTRODUCTION}

The hip joint is one of the joints that is exposed to the most load and shows a lot of wear in the musculoskeletal system. This joint which moves in the sagittal, frontal and horizantal planes forms the connection between the trunk and the lower extremity [1]. The hip joint faces loads both in situations that require excessive force and while doing the essential activities of daily life, such as climbing stairs [2, 3]. Loading a joint above the normal load can damage it and cause arthritis.

Surgical replacement of the hip joint with an artificial prosthesis or total hip arthroplasty (THA) is a reconstructive procedure that provides management of hip joint diseases that respond poorly to traditional medical therapy [4]. The goal in THA practice is to eliminate pain and increase function.

Restoration of muscular strength is important for daily life activities after total hip arthroplasty [5]. In studies that examined muscle strength after THA surgery, it was stated that significant improvements in muscle strength were observed at the 6th month and beyond after surgery. Studies have consistently reported significant improvements in muscle strength at 6-month follow-up compared to preoperative values [6-8]. However, in some studies, it is thought that such comparisons may not give very accurate results. The preoperative complaints of patients considering THA surgery include pain and a loss of function. This situation may cause a decrease in muscle strength due to pain and immobility of the operated side and prevent it from showing the actual muscle strength. Therefore, there is an opinion that a comparison of muscle strength should be made with the side that was not operated on, not with the preoperative values [3]. Therefore, this study compared the operated and non-operated side for the evaluation of hip muscle strength.

It is important to determine the presence of asymmetry in the muscle strength and the range of motion (ROM) between the operated side and the non-operated side, because a possible asymmetry that occurs may affect the functional status of patients with THA and cause a restriction in daily life activities. Therefore, it would be clinically relevant to examine this situation. The purpose of this study was to compare muscle strength and the range of motion of the operated side and the unoperated side and determine the relationship between the functional status with muscle strength and the range of motion in patients with THA 1-3 years after surgery. We hypothesized that the muscle strength of the operated side would be significantly lower than the unoperated side and that the hip ROM of the operated side would be smaller than of the unoperated side.

\section{MATERIAL AND METHODS}

\section{Patients}

In this study, 50 patients who underwent THA surgery between the ages of 40-65 by an orthopedist in Hacettepe University Faculty of Medicine Department of Orthopedics and Traumatology were evaluated in accordance with the annual outpatient controls. In order to conduct the study, approval was obtained from the Hacettepe University NonInterventional Clinical Research Ethics Committee with the decision number GO17/87831. This study involved volunteers who had undergone unilateral THA surgery for at least 1 , at most 3 years, and had no cooperation or communication problems. Individuals who had undergone lower extremity surgery other than THA, had signs of active infection, and had a history of THA revision or dislocation were excluded from the study. Prior to the assessments, participants were informed in writing and orally about the purpose, duration and measurements of the study. Individuals involved in the study signed an informed consent form that they were willing to participate in the study. 


\section{Measurements of the hip range of motion}

A 360-degree universal goniometer was used to measure the range of motion of the hip [9]. Patients were positioned supine for the flexion, abduction and adduction measurements, prone for the extension measurement, and sitting for the internal and external rotation movement measurements. Prior to taking the measurements, the subjects were taught the movement. All measurements were performed 3 times, and the mean was recorded. Each measurement was performed on the operated and the non-operated side.

For flexion and extension movements, the pivot point of the goniometer was placed in the trochanter major of the femur. The fixed arm was held parallel to the vertebral column. The movable arm followed the lateral midline of the femur. During the extension measurement, the pelvic elevation and the lordosis angle were taken into consideration.

For abduction and adduction movements, the pivot point of the goniometer was placed on the projection of the trochanter major on the anterior face of the femur. The fixed arm was kept parallel to the spina iliac anterior superior. The movable arm followed the anterior midline of the femur. For internal and external rotation, individuals were seated with their legs hanging from the knee. The pivot point of the goniometer was placed in the tuberositas tibia. The fixed arm was held parallel to the ground. The movable arm followed the crista of the tibia. During the measurement, it was ensured that hip flexion, extension, abduction and adduction movements did not occur.

\section{Muscle strength measurements}

Different methods, such as a manual muscle test, a 1-2 repetitive maximum test, an isokinetic and isometric dynamometers and a hand-held dynamometer (HHD), are used in the clinic for strength evaluations [10]. HHD, which measures the maximum isometric muscle strength, is a simple to use, easy-to-carry, inexpensive and valid instrument for measuring muscle strength around the hip [11]. Flexion, extension, abduction muscle strength of both hip joints and extension muscle strength of both knees were measured by a hand-held dynamometer (Model-01165, Lafayette Instrument Company, Lafayette IN, USA) and recorded in $\mathrm{kg}$. Each subject was informed verbally about the test technique prior to the test. Before starting measurements, individuals were asked to perform submaximal contraction against the evaluator's hand to ensure correct movement [11]. The "break test" technique, which requires isometric contraction, was used in the measurements. In the break test, the tester pushes the dynamometer against the patient's limb until movement is released in the joint to overcome the maximum muscle strength [12]. In all muscle strength measurements, individuals were asked to maintain isometric contraction for 5 seconds for the desired movement to be measured. The mean of 3 consecutive maximum contractions measured at 30-second intervals was recorded. Each measurement was performed on the operated and non-operated side [13].

For the knee extension and hip flexion muscle strength measurement, individuals were asked to sit with their legs hanging from knees, knees at $90^{\circ}$ flexion, feet free, arms crossed on the chest and without support. During the measurement of knee extension muscle strength, the leg was stabilized with one hand after individuals had completed the maximum knee extension. The hand holding the dynamometer was placed perpendicular to the leg 1-2 cm above the level of the malleol (Figure 1). In the hip flexion muscle strength measurement, the leg which was not applied was stabilized with one hand after individuals completed the maximum hip flexion. The hand holding the dynamometer was placed $5 \mathrm{~cm}$ proximal to the patella. The measurement was performed after the maximum hip flexion occurred (Figure 2). 
For the hip abduction muscle strength measurement, patients were placed in the sidelying position for the test. After the subjects had completed the maximum hip abduction movement, a hand was placed on the pelvis to provide stabilization. The other hand holding the dynamometer was placed $5 \mathrm{~cm}$ proximal to the lateral malleol for measurement. The measurement was performed in this position (Figure 3).

For the hip extension muscle strength tmeasurement, patients were positioned prone. After the individuals had completed the maximum hip extension during the test, the pelvis was stabilized with one hand to prevent elevation of the pelvis. The hand holding the dynamometer was placed $5 \mathrm{~cm}$ proximal to the knee joint. The measurement was performed after completion of the maximum hip extension (Figure 4).

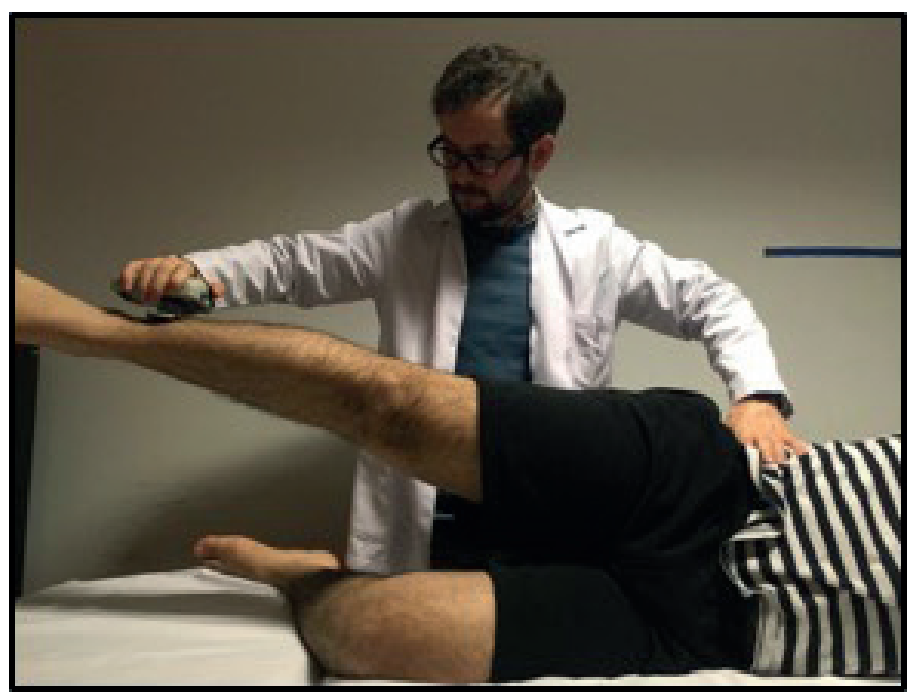

Fig. 1.

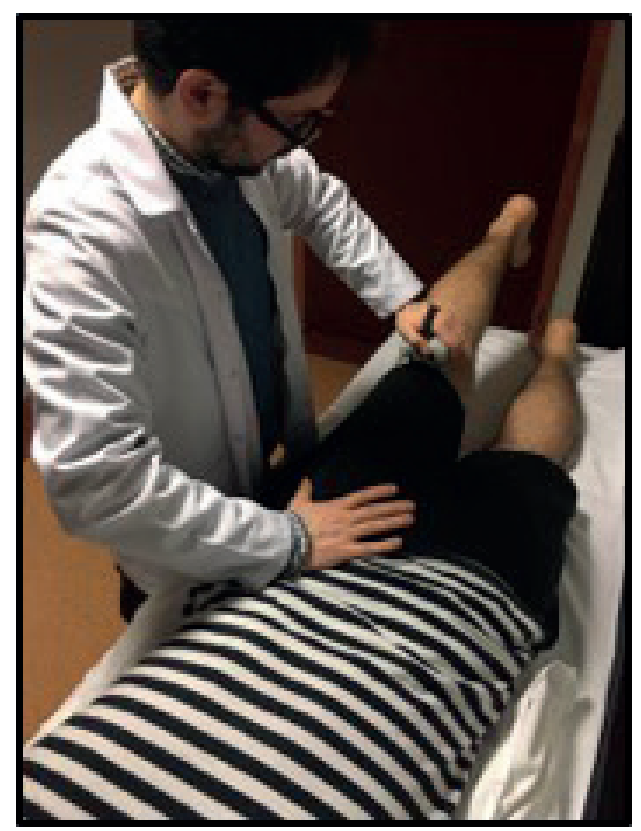

Fig. 2. 


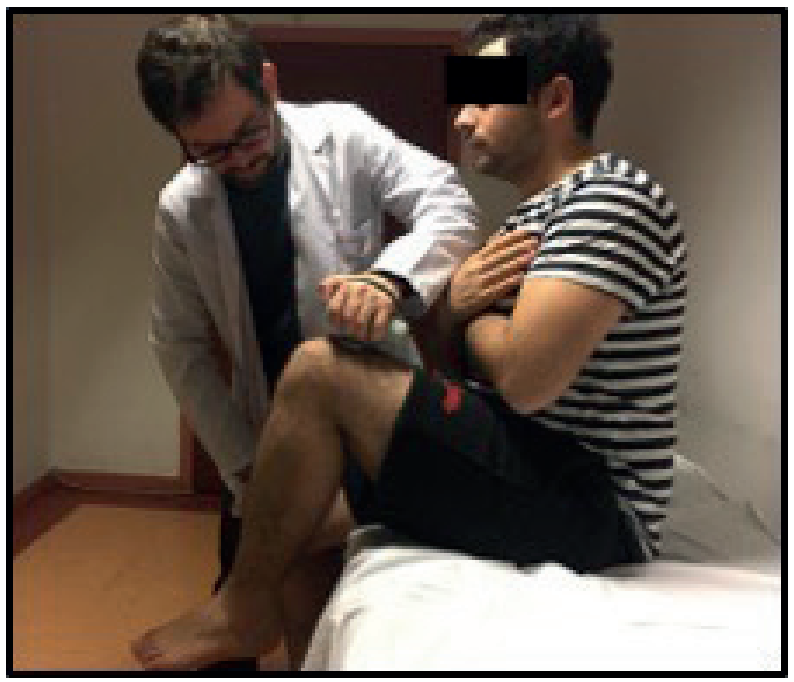

Fig. 3.

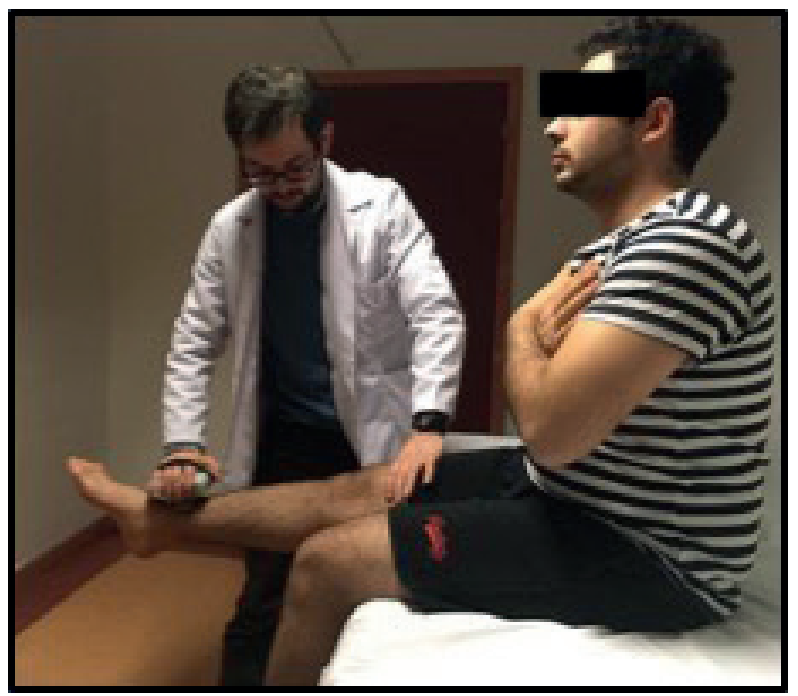

Fig. 4.

\section{ASSESSMENT OF THE FUNCTIONAL STATUS}

The Turkish version of the Oxford Hip Score (OHS) was used to evaluate pain and functional conditions of the patients involved in the study [14]. OHS is a commonly used scale to assess pain and the functional status in patients undergoing hip surgery [15]. It has been shown to have good reliability, validity, and sensitivity to clinical change [16]. OHS consists of 12 questions related to the patient's perceived pain and functional status and is answered on a Likert scale from 0 to 4 . It scores between 0 and 48 and the total score is calculated from the answers given to 12 questions. A low score indicates that functional status is bad.

\section{STATISTICAL ANALYSIS}

The data obtained were evaluated with IBM SPSS 20.0 package program. The normal distribution of the variables was determined by visual (histogram and probability graphs) and analytical methods (Kolmogorov-Smirnov / Shapiro-Wilk tests). Descriptive analyses, means and standard deviations for numerical variables are shown. The Wilcoxon test or paired student's t-test was used to compare hip ROM and muscle strength of the operated 
and the unoperated side depending on whether the variables were normally distributed or not. Correlation coefficients and statistical significance were determined using the Spearman test since the data were not normally distributed. Type-1 error level was used as $5 \%$ for statistical significance $(p<0.05)$ [17].

\section{RESULTS}

In this cross-sectional study, 50 patients (39 females; 11 males) were evaluated. The participants' physical characteristics are shown in Table 1.

Table 1. Physical characteristics of the patients

\begin{tabular}{cc}
$\mathrm{n}=50$ & THA X \pm SD \\
\hline Age (years) & $55.90 \pm 7.5$ \\
Length Length $(\mathrm{cm})$ & $163.06 \pm 9.6$ \\
Body weight $(\mathrm{kg})$ & $75.24 \pm 13.4$ \\
Body Mass Index $\left(\mathrm{kg} / \mathrm{m}^{2}\right)$ & $28.15 \pm 4.4$ \\
\hline
\end{tabular}

$\mathrm{n}=$ Number of patients, THA: Total Hip Arthroplasty, $\mathrm{X} \pm$ SD: Mean \pm Standard Deviation

Table 2 shows the minimum and maximum values of the ROM and muscle strength of the patients' operated and unoperated hip.

Table 2. The ROM and muscle strength of the operated and unoperated side of hip

\begin{tabular}{lcc} 
& $\begin{array}{c}\text { Operated side } \\
\text { Min. - Max. }\end{array}$ & $\begin{array}{c}\text { Unoperated side } \\
\text { Min. - Max. }\end{array}$ \\
\hline Hip Range of Motion $\left(^{\circ}\right)$ & $30-123$ & $50-130$ \\
Flexion & $0-10$ & $0-10$ \\
Extension & $10-45$ & $15-45$ \\
Abduction & $0-10$ & $5-10$ \\
Adduction & $0-42$ & $2-45$ \\
Internal Rotation & $0-45$ & $3-40$ \\
External Rotation & & \\
\hline Muscle Strength $(\mathrm{kg})$ & $4.53-28.20$ & $4.41-34.30$ \\
Hip flexion & $4.28-25.5$ & $4.19-24.20$ \\
Hip extension & $2.96-22.60$ & $3.45-29.20$ \\
Hip abduction & $4.71-28.11$ & $4.82-33.00$ \\
Knee extension & & \\
\hline
\end{tabular}

A comparison of the hip joint range of motion between operated and unoperated sides is shown in Table 3.

While there was a statistically significant difference between the patients' operated and the non-operated side in hip flexion, extension, abduction, internal and external rotation range of motion $(p<0.001)$, there was no statistically significant difference between the patients' operated and non-operated side in the adduction range of motion $(p>0.05)$. 
Table 3. Comparison of joint range of motion the operated and unoperated side

\begin{tabular}{|c|c|c|c|c|c|}
\hline \multirow{2}{*}{ Hip ROM $\left({ }^{\circ}\right)$} & \multicolumn{2}{|c|}{ Operated side } & \multicolumn{2}{|c|}{ Unoperated side } & \multirow{2}{*}{$p$} \\
\hline & $X \pm S D$ & Median (IQR) & $X \pm S D$ & Median (IQR) & \\
\hline Flexion & $83.52 \pm 19$ & $88.30(27.50)$ & $96.52 \pm 17$ & $100(22.25)$ & $<0.001 *$ \\
\hline Extension & $3.38 \pm 4$ & $2.0(7.25)$ & $4.8 \pm 4$ & $5.0(10)$ & $<0.001 \dagger$ \\
\hline Abduction & $28.44 \pm 9$ & $28.5(15)$ & $36.68 \pm 8$ & $40(15)$ & $<0.001 \dagger$ \\
\hline Adduction & $9.5 \pm 1$ & $10(0)$ & $9.9 \pm 0.7$ & $10(0)$ & 0.109 \\
\hline Internal Rotation & $23.32 \pm 8$ & $22.75(10)$ & $26.32 \pm 1$ & 27.50 (15) & $<0.001^{*}$ \\
\hline External Rotation & $11.36 \pm 8$ & $10(5.5)$ & $19.22 \pm 7$ & $20(10.5)$ & $<0.001 \dagger$ \\
\hline
\end{tabular}

*Paired student's t-test, +Wilcoxon Test, ROM: Range of motion, X \pm SD: Mean \pm Standard Deviation, IQR: Interquartile range

The comparison of hip and knee muscle strength between the patients' operated and nonoperated sides is shown in Table 4.

While there was no statistically significant difference between the operated and nonoperated sides in the hip flexion and extension muscle strength values $(p>0.05)$, there was a statistically significant difference between the operated and non-operated sides in hip abduction muscle strength and knee extension muscle strength values in favor of the non-operated side $(\mathrm{p}<0.001)$

Table 4. Comparison of operated and non-operated side muscle strength of patients

\begin{tabular}{|c|c|c|c|c|}
\hline Muscle Strength $(\mathrm{kg})$ & $\begin{array}{l}\text { Operated side } \\
\text { Median (IQR) }\end{array}$ & $\begin{array}{c}\text { Unoperated side } \\
\text { Median (IQR) }\end{array}$ & Z & $p$ \\
\hline Hip flexion & $8.29(9.65)$ & $8.62(7.61)$ & -0.632 & 0.528 \\
\hline Hip extension & $7.52(7.82)$ & $7.94(8.29)$ & -0.332 & 0.740 \\
\hline Hip abduction & $9.1(8.07)$ & $9.70(8.60)$ & -3.249 & $<0.001 *$ \\
\hline Knee extension & $9.66(10.5)$ & $10.37(11.21)$ & -2.254 & $<0.001 *$ \\
\hline
\end{tabular}

Correlations of OHS with muscle strength and range of motion are shown in Table 5.

There was a moderately significant correlation between OHS with hip flexion, extension, abduction muscle strength, and hip adduction ROM.

Table 5. Correlation of OHS with muscle strength and ROM

\begin{tabular}{lcc} 
& & OHS \\
\cline { 2 - 3 } & $r$ & $\mathrm{p}$ \\
\hline Muscle strength & $\mathbf{0 . 3 9 7}$ & \\
Hip flexion & $\mathbf{0 . 4 7 0}$ & 0.005 \\
Hip extension & $\mathbf{0 . 4 0 1}$ & 0.001 \\
Hip abduction & $\mathbf{0 . 4 0 7}$ & 0.005 \\
Knee extension & & 0.004 \\
Hip ROM ( ${ }^{\circ}$ ) & 0.111 & \\
\hline Flexion & 0.257 & 0.448 \\
Extension & -0.026 & 0.74 \\
Abduction & $\mathbf{0 . 4 4 6}$ & 0.861 \\
Adduction & 0.105 & 0.001 \\
Internal Rotation & 0.323 & 0.472 \\
External Rotation & & 0.024 \\
\hline r: Spearmancorration & &
\end{tabular}




\section{DISCUSSION}

The results of our study showed that there was a difference in favor of the unoperated side between the operated and unoperated sides in hip ROM except for hip adduction. In addition, a significant difference was found between the hip abduction and knee extension muscle strength in favor of the unoperated side. Also, the functional status correlated with muscle strength.

The ROM of the hip joint is important for performing the functions of the hip joint during daily life activities, such as climbing stairs, putting on socks, tying shoes, sitting down and getting up off a chair. Daily life activities require at least 120 degree hip flexion, 20 degree hip abduction and external rotation and full hip extension in the hip joint $[18,19]$.

Postoperative hip ROM limitation is a controversial issue. Long et al. [20] found a 10 degree ROM asymmetry in the first year after surgery. In contrast, Yamaguchi et al. [21] did not find any difference in ROM between the operated and unoperated side after surgery. In this study, the patients' flexion range in the operated side was $13.6 \%$, extension range $29.8 \%$, abduction range $25.51 \%$, adduction range $3.8 \%$, internal rotation range $13.44 \%$ and external rotation range $45.08 \%$ less than in the unoperated side. Surprisingly and contrary to the literature, the ROM difference in our study was greater. This study results revealed that patients with THA need to be evaluated in terms of ROM in the long term after surgery and that appropriate physiotherapy practise should be performed. This result could be important in terms of follow-up and home program exercises after discharge. This limitation in hip ROM may cause difficulties in some of the patients' daily life activities. In particular, patients stated that they had a serious problem in the 4th question of OHS: „Have you been able to put on a pair of socks, stockings or tights?” This may be due to the limitation in hip flexion ROM.

Patients are routinely informed by post-surgical physiotherapists about dislocation positions to be considered during the hospital stay. Afterwards, patients are discharged from the follow-up, and they still maintain these dislocation positions taught during hospitalization because they are concerned about harming surgery. Therefore, they are confused about when to stop dislocation positions after surgery. This creates a continuing protection reflex in these patients, although adequate time has elapsed since surgery. As a result, patients may still avoid performing certain activities involving the hip joint, thus limiting their joints. Therefore, we think that the cause of this joint movement limitation in patients is fear of dislocation. We think that if the necessary information is given about how long dislocation positions should be paid attention to after-surgery patients, it may be possible to prevent joint movement limitations.

In the postoperative period, the muscle strength balance on the operated and non-operated sides is important for the life of the prosthesis. Trudelle-Jackson et al. [2], who examined the hip muscle strength of the operated and unoperated side 1 year after THA, stated that in the operated side hip muscle strength of the patients was about 10-18\% less than the unoperated side. Similarly, Shih et al. [6] found an approximately 11-21\% strength loss in their studies compared to the unoperative side at 1 year after surgery. In this study, when the strength of the muscles surrounding the hip of the operated and unoperated side was compared, there was a $7.55 \%$ loss of strength in the operated side hip abduction and $7.01 \%$ in the knee extension muscle strength. Contrary to these studies [2,6], the lower muscle strength deficit in our study may be due to examining the late results (mean 2.06 years) of the evaluated patients after surgery. In the current study, the knee extension muscle strength of the operated side was statistically lower than on the unoperated side. This may be due to the low usage of the operated side knee to protect the surgery. This muscle strength imbalance between the operated and the unoperated side can cause more intense use of the unoperated side during daily life activities. This use can create 
asymmetry during loading in the joint and, accordingly, may cause the development of $\mathrm{OA}$ in the unoperated side knee and hip joint in the future. In addition, weakness in the operated side muscle strength can prevent the maintenance of the prosthesis fixation and cause the prosthesis to loosen, reducing the lifetime of the prosthesis.

Another result of this study is that, while there was no statistically significant difference between the operated and unoperated side in the hip flexion and extension muscle strength, there was a statistically significant difference between the operated and unoperated side in hip abduction muscle strength in favor of the unoperated side. The reason for this may be a rehabilitation program that includes strengthening exercises routinely applied to individuals during the hospital stay after TKA surgery. Exercises performed by patients in this process may have reached the level of the unoperated side.

Abduction muscle strength is important for gait and hip biomechanics. It has been stated that abductor muscle weakness can lead to impaired joint stability, which can result in highly recurrent dislocation [22]. Therefore, the protection of the gluteus medius muscle during THA surgery is very important for postoperative abduction muscle strength and functional outcome. It has been reported that gluteus medius muscles show a serious cross-sectional area and loss of radiological intensity in adult patients with unilateral congenital hip dislocation. Abductor force arm and change of gluteus medius muscle activation angle have been reported as factors affecting gluteus medius muscle strength [23]. Therefore, a decrease in gluteus medius muscle strength is a condition that can be seen from the pre-surgical period.

The difference in hip abduction muscle strength between the operated and unoperated side was statistically significant. We think that this situation may be caused by patients with developmental hip dysplasia evaluated in our study. Changing the cross-sectional area and density of gluteus medius muscle fibers in the patients with the developmental displacement of the hip since the preoperative period may cause the muscle to be insufficient in performing the function in the postoperative period.

OHS evaluates pain and the functional state of the hip in relation to daily activities such as walking, dressing and sleeping. In their studies evaluating physical function after total hip arthroplasty, Matsunaga-Myoji et al. [24] found the OHS result to be 42.7 points in the first year and 44.8 points in the third year. In their study of the use of Oxford hip and knee scores, Murray et al. [15] found the patients' mean OHS scores of 37.6 in the first year after hip arthroplasty. Similarly to those studies, the mean OHS of the patients in our study was 37.80 points. This result is an indication that the functional condition is relatively good. Contrary to our and other studies, Mjaaland et al. [25] found the Oxford hip score of 19.5 points in the first year and 26 points in the second year in their study in which they examined the results of total hip arthroplasty. This poor functional status may be due to the use of different surgical approaches, such as direct anterior and lateral. In our study, the same surgical approach was used.

Also the OHS scores were correlated with muscle strength. The relationship between the muscle strength and the functional status found in this study shows the importance of muscle strength for independence in daily life activities. It shows that sufficient muscle strength is needed for a good functional status.

This study has a limitation. The major limitation of this study is that the patients in the study had different diagnoses, such as femoral fracture, developmental hip dysplasia, and hip osteoarthritis. This situation may affect the difference in the muscle strength and the range of motion results between the operated and unoperated sides in our study. 


\section{CONCLUSIONS}

This study emphasizes the importance that these patients need physiotherapy programs in the long term and should be followed up regularly by healthcare professionals in the rehabilitation area. Finally, we recommend restoring muscle strength and especially the range of motion to improve the functional status in daily life activities.

\section{AKCNOWLEDGEMENTS}

The authors would like to thank all the patients and thank the Hacettepe University for providing equipment assistance for this study.

\section{REFERENCES}

[1] Luepongsak N, Amin S, Krebs D, McGibbon C, Felson D. The contribution of type of daily activity to loading across the hip and knee joints in the elderly. Osteoarthritis Cartilage. 2002;10(5):353-359. https://doi.org/10.1053/joca.2000.0511

[2] Trudelle-Jackson E, Emerson R, Smith S. Outcomes of total hip arthroplasty: A study of patients one year postsurgery. J Orthop Sports Phys Ther. 2002;32(6):260-267. https://doi.org/10.2519/jospt.2002.32.6.260

[3] Trudelle-Jackson E, Smith SS. Effects of a late-phase exercise program after total hip arthroplasty: A randomized controlled trial1, 2. Arch Phys Med Rehabil. 2004;85(7):1056-1062. https://doi.org/10.1016/j.apmr.2003.11.022

[4] Siopack JS, Jergesen HE. Total hip arthroplasty. West J Med. 1995;162(3):243-249.

[5] Winther SB, Husby VS, Foss OA, et al. Muscular strength after total hip arthroplasty: A prospective comparison of 3 surgical approaches. Acta Orthop. 2016;87(1):22-28. https://doi.org/10.3109/17453674.2015.1068032

[6] Shih C-H, Du Y-K, Lin Y-h, Wu C-C. Muscular recovery around the hip joint after total hip arthroplasty. Clin Orthop Relat Res. 1994(302):115-120. https://doi.org/10.1097/00003086-199405000-00019

[7] Rasch A, Dalén N, Berg HE. Muscle strength, gait, and balance in 20 patients with hip osteoarthritis followed for 2 years after THA. Acta Orthop. 2010;81(2):183-188. https://doi.org/10.3109/17453671003793204

[8] Häkkinen A, Borg H, Kautiainen H, et al. Muscle strength and range of movement deficits 1 year after hip resurfacing surgery using posterior approach. Disabil Rehabil. 2010;32(6):483-491. https://doi.org/10.3109/09638280903171451

[9] Otman S, Demirel H, Sade A. Tedavi Hareketlerinde Temel Değerlendirme Prensipleri [Basic Evaluation Principles in Treatment Movements]. Ankara: Hacettepe Üniversitesi Fizik Tedavi ve Rehabilitasyon Yayınları 16, 2 Baskı. 1998. Turkish.

[10] Suzuki M, Yamada S, Inamura A, et al. Reliability and validity of measurements of knee extension strength obtained from nursing home residents with dementia. Am J Phys Med Rehabil. 2009;88(11):924-933. https://doi.org/10.1097/ PHM.0b013e3181ae1003

[11] Thorborg K, Petersen J, Magnusson S, Hölmich P. Clinical assessment of hip strength using a hand-held dynamometer is reliable. Scand J Med Sci Sports. 2010;20(3):493-501. https://doi.org/10.1111/j.1600-0838.2009.00958.x

[12] Van der Ploeg R, Oosterhuis H. The" make/break test" as a diagnostic tool in functional weakness. J Neurol Neurosurg Psychiatry. 1991;54(3):248-251. https://doi.org/10.1136/jnnp.54.3.248

[13] Bohannon RW. Alternatives for measuring knee extension strength of the elderly at home. Clin Rehabil. 1998;12(5):434440. https://doi.org/10.1191/026921598673062266

[14] Tuğay BU, Tuğay N, Güney H, Hazar Z, Yüksel I, Atilla B. Cross-cultural adaptation and validation of the Turkish version of Oxford hip score. Arch Orthop Trauma Surg. 2015;135(6):879-889. https://doi.org/10.1007/s00402-015-2215-9

[15] Murray D, Fitzpatrick R, Rogers K, et al. The use of the Oxford hip and knee scores. Bone Joint J. 2007;89(8):10101014. https://doi.org/10.1302/0301-620X.89B8.19424

[16] Nilsdotter A, Bremander A. Measures of hip function and symptoms: Harris Hip Score (HHS), Hip Disability and Osteoarthritis Outcome Score (HOOS), Oxford Hip Score (OHS), Lequesne Index of Severity for Osteoarthritis of the Hip (LISOH), and American Academy of Orthopedic Surgeons (AAOS) Hip and Knee Questionnaire. Arthritis Care Res. 2011;63(S11):200-207. https://doi.org/10.1002/acr.20549

[17] Hayran M, Hayran M. Sağlık Araştırmaları İçin Temel İstatistik (1. Basım) [Basic Statistics for Health Research (1st Edition)]. Art Ofset Matbaacılık Yayıncılık Organizasyon Ankara Sayfa. 2011;95.

[18] Goldstein TS, Lewis CB. Geriatric orthopaedics: Rehabilitative management of common problems. 1999.

[19] Kisner C, Colby LA, Borstad J. Therapeutic exercise: Foundations and techniques: Fa Davis; 2017.

[20] Long WT, Dorr LD, Healy B, Perry J. Functional recovery of noncemented total hip arthroplasty. Clin Orthop Relat Res. 1993(288):73-77. https://doi.org/10.1097/00003086-199303000-00009

[21] Yamaguchi T, Naito M, Asayama I, Kambe T, Fujisawa M, Ishiko T. The effect of posterolateral reconstruction on range of motion and muscle strength in total hip arthroplasty. J Arthroplasty. 2003;18(3):347-531. https://doi.org/10.1054/ arth.2003.50060

[22] Kiyama T, Naito M, Shitama H, Maeyama A. Effect of superior placement of the hip center on abductor muscle strength in total hip arthroplasty. J Arthroplasty. 2009;24(2):240-245. https://doi.org/10.1016/j.arth.2008.08.012

[23] Liu R, Wen X, Tong Z, Wang K, Wang C. Changes of gluteus medius muscle in the adult patients with unilateral developmental dysplasia of the hip. BMC Musculoskelet Disord. 2012;13(1):101. https://doi.org/10.1186/1471-247413-101 
[24] Matsunaga-Myoji Y, Fujita K, Makimoto K, Tabuchi Y, Mawatari M. Three-Year Follow-Up Study of Physical Activity, Physical Function, and Health-Related Quality of Life After Total Hip Arthroplasty. J Arthroplasty. 2020;35(1):198203. https://doi.org/10.1016/j.arth.2019.08.009

[25] Mjaaland KE, Kivle K, Svenningsen S, Nordsletten L. Do postoperative results differ in a randomized trial between a direct anterior and a direct lateral approach in THA? Clin Orthop Relat Res. 2019;477(1):145-155. https://doi. org/10.1097/CORR.0000000000000439 